\title{
Cervical Radiograph of a Patient with Cervicogenic Dizziness
}

\section{Gary Shum $^{1 *}$, Wayne Whittingham ${ }^{2}$, Sally Cinnamond ${ }^{1}$, Sherrie Choy ${ }^{3}$ and Alan Hough ${ }^{3}$}

${ }^{1}$ Faculty of Sport and Health Sciences, University of St Mark and St John, Plymouth PL6 8BH, United Kingdom

${ }^{2}$ Plymouth Chiropractic Clinic, Plymouth, United Kingdom

${ }^{3}$ Livewell Southwest, NHS, Plymouth, United Kingdom

${ }^{*}$ Corresponding author: Gary Shum, Faculty Director of Research, Associate Professor, Faculty of Sport and Health Sciences, University of St Mark and St John, Plymouth PL6 8BH, United Kingdom, Tel: 01752636700 (Ext. 5310); E-mail: gshum@marjon.ac.uk

Rec date: Jun 25, 2016; Acc date: Jun 27, 2016; Pub date: Jun 29, 2016

Copyright: () 2016 Shum G, et al. This is an open-access article distributed under the terms of the Creative Commons Attribution License, which permits unrestricted use, distribution, and reproduction in any medium, provided the original author and source are credited.

\section{Clinical Image}

This is a cervical X-ray of a patient suffering from long term dizziness and associated neck pain and stiffness. The X-ray showed that the $\mathrm{C} 1$ cervical vertebrae were in a rotated position (Figure 1).

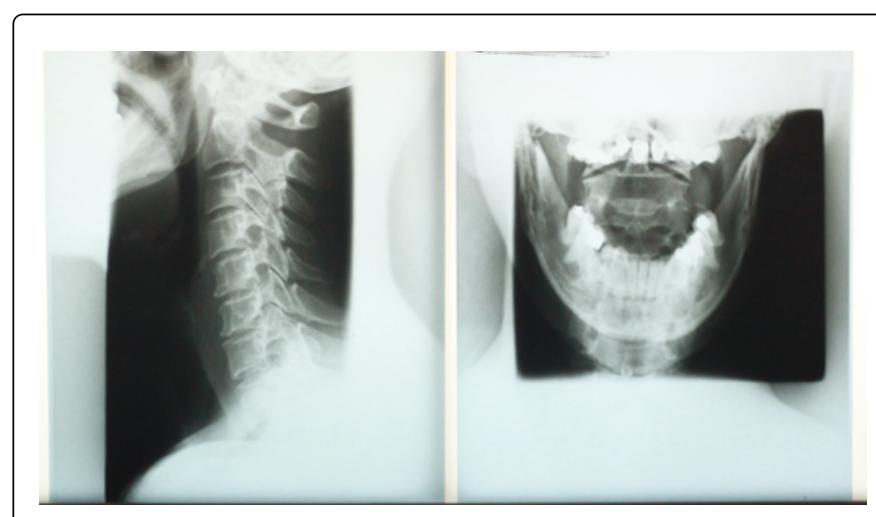

Figure 1: Cevicogenic dizziness.

In some cases of dizziness, one of the causes can be attributed to pathology or dysfunction of upper cervical spine [1-3]. Poor head and neck posture and mal-aligned upper cervical spine may cause a decreased vertebrobasilar blood flow and contribute to dizziness [4,5]. This form of dizziness can be diagnosed as cervicogenic dizziness. There is a strong correlation in the improvement in the neck symptoms and dizziness [6].

\section{References}

1. Brandt T, Bronstein AM (2001) Cervical vertigo. J Neurol Neurosurg Psychiatry 71: 8-12.

2. Heikkila H, Johansson M, Wenngren BI (2000) Effects of acupuncture, cervical manipulation and NSAID therapy on dizziness and impaired head repositioning of suspected cervical origin: a pilot study. Man Ther 5: 151-157.

3. Wrisley DM, Sparto PJ, Whitney SL, Furman JM (2000) Cervicogenic dizziness: a review of diagnosis and treatment. J Orthop Sports Phys Ther 30: 755-766.

4. Biesinger E (1988) Vertigo caused by disorders of the cervical vertebral column. Diagnosis and treatment. Adv Otorhinolaryngol 39: 44-51.

5. Fitz-Ritson D (1991) Assessment of cervicogenic vertigo. J Manipulative Physiol Ther 14: 193-198.

6. Shum G, Whittingham W, Cinnamond S (2013) Evaluation of a course of cervical adjustments in treating cervicogenic dizziness. Conference Proceedings of European Chiropractors Union Convention. 